\title{
AS TICS COMO SUPORTE AO PATRIMÔNIO PÚBLICO CULTURAL: PROJETO dE digitALIZAÇÃO do ACERVO do ARQUIVO HISTÓRICO DO MUNICÍPIO DE ARARANGUÁ-SC
}

THE ICTS AS A SUPPORT TO THE PUBLIC CULTURAL HERITAGE: PROJECT OF DIGITIZATION OF THE ARCHIVE OF THE HISTORICAL ARCHIVE OF THE MUNICIPALITY OF ARARANGUÁ-SC

LAS TICS COMO APOYO AL PATRIMONIO CULTURAL PÚBLICO: PROYECTO DE DIGITALIZACIÓN DEL COLECCIÓN DEL ARCHIVO HISTÓRICO DEL MUNICIPIO DE ARARANGUÁ-SC

${ }^{1}$ Gabrielli Ciasca Veloso, ${ }^{1}$ Andréa Cristina Trierweiller, ${ }^{1}$ Paulo César Leite Esteves

${ }^{1}$ Universidade Federal de Santa Catarina

\section{Correspondência}

${ }^{1}$ Gabrielli Ciasca Veloso.

1Universidade Federal de Santa Catarina . Araranguá, SC.

Email: velosogabrielli@gmail.com

ORCID: http://orcid.org/0000-0003-3918-

$\underline{4532}$

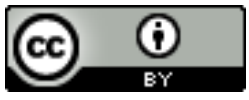

JITA: JH. Digital preservation. 
RESUMO: A principal função das Tecnologias da Informação e Comunicação (TICs) diz respeito a favorecer a disseminação e compartilhamento da informação, por meio de ferramentas que auxiliem na comunicação de modo geral. Um ambiente que caracteriza e oportuniza este processo de comunicação entre pessoas, épocas e lugares, com base na informação que mantém em diversos formatos, é o Museu, ou Arquivo Histórico. No entanto, o que percebemos é que a visita ao museu não é mais a principal fonte de informações, lembrada no momento da pesquisa, e é neste contexto que as ditas TICs, podem contribuir. A aplicação de instrumentos e mecanismos computacionais no contexto museólogo, não provoca só a modernização, mas busca facilitar a investigação e recolhimento de informações, além de assumir, sobretudo, uma posição de complemento ao museu, não de "competição", com o que nunca deixará de ser o ambiente de salvaguarda da história. Neste trabalho, buscou-se descrever o projeto e os processos de digitalização e disponibilização virtual do acervo histórico do município de Araranguá-SC e relatar suas consequências quanto à conservação e difusão do acervo digitalizado.

PALAVRAS-CHAVE: Acervo digital. Digitalização. Tecnologias da informação e comunicação.

ABSTRACT: The main function of Information and Communication Technologies (ICTs) is to promote the dissemination and sharing of information, through tools that aid communication in general. An environment that characterizes and facilitates this process of communication between people, times and places, based on the information it maintains in various formats, is the Museum, or Historical Archive. However, what we realize is that the visit to the museum is no longer the main source of information, remembered at the time of the research, and it is in this context that the said ICTs can contribute. The application of computational tools and mechanisms in the museological context, not only causes modernization, but also seeks to facilitate the investigation and gathering of information, besides assuming, above all, a position of complement to the museum, not of "competition", with which never will no longer be the safeguarding environment of history. This work aimed to describe the project and the processes of digitalization and virtual availability of the historical collection of the municipality of Araranguá-SC and report its consequences regarding the conservation and diffusion of the digitized collection.

KEYWORDS: Digital heritage. Digitization. Information and communication technologies.

RESUMEN: La principal función de las Tecnologías de la Información y la Comunicación (TIC) se refiere a favorecer la difusión y el intercambio de información a través de herramientas que ayuden en la comunicación en general. Un ambiente que caracteriza y oportuniza este proceso de comunicación entre personas, épocas y lugares, con base en la información que mantiene en diversos formatos, es el Museo, o Archivo Histórico. Sin embargo, lo que percibimos es que la visita al museo ya no es la principal fuente de información, recordada en el momento de la investigación, y es en este contexto que las dichas TIC, pueden contribuir. La aplicación de instrumentos y mecanismos computacionales en el contexto museológico, no provoca sólo la modernización, sino que busca facilitar la investigación y recogida de informaciones, además de asumir, sobre todo, una posición de complemento al museo, no de "competencia", con lo que nunca dejará de ser el ambiente de salvaguardia de la historia. En este trabajo, se buscó describir el proyecto y los procesos de digitalización y puesta a disposición virtual del acervo histórico del municipio de Araranguá-SC y relatar sus consecuencias en la conservación y difusión del acervo digitalizado.

PALABRAS CLAVE: Colección digital. Digitalización. Tecnologías de la información y la comunicación.

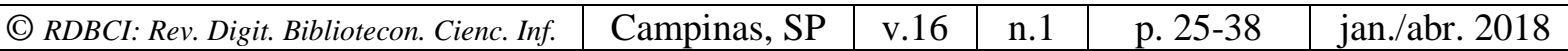




\section{INTRODUÇÃo}

O material histórico cresce a cada novo acontecimento registrado. No entanto, Museus e Arquivos, isoladamente, não têm como competir com a densidade informacional que a internet e demais ferramentas de informação e comunicação proporcionam, uma vez que a interação com uma exposição virtual, seu compartilhamento e facilidade de acesso, pode parecer mais atrativa e está cada vez mais simples e intuitiva de se manejar.

Essas tecnologias de acesso e compartilhamento trazem a possibilidade de difusão abrangente e de fácil propagação do patrimônio dos Museus, Arquivos Históricos, Centros Culturais e Exposições, sejam temporárias ou permanentes. Por meio da percepção desse desenvolvimento, fascinante e acelerado da tecnologia, diversos espaços públicos, fora e dentro do Brasil, vem se adaptando à utilização de ferramentas da informática. Sua efetivação, é capaz de tornar acessíveis, informações relacionadas ao contexto em que se apresentam. Assim, Museus e Centros Culturais se utilizam destas ferramentas não somente na criação de web sites informativos sobre suas exposições, mas, também como meio de intercâmbio de informações entre especialistas e visitantes "leigos". Ou ainda, como um meio alternativo de divulgação dos projetos desenvolvidos.

A boa implementação dessas ferramentas, pode, sobretudo, proporcionar um complemento ao Museu físico. Por meio de exposições virtuais e disponibilização de informações adicionais sobre o conteúdo do Museu, é possível proporcionar diferentes meios de acesso a esses materiais. Em situações mais extremas, que podem resultar em risco a integridade do patrimônio (como por exemplo, o material que necessita de restauro ou que se encontra guardado em isolamento por motivos de preservação preventiva), o acesso pela população poderá ser prejudicado ou impedido. Em circunstâncias como essas, as Tecnologias da Informação e comunicação (TIC) também tem o potencial de servir como ponte. No entanto, como com qualquer tecnologia, se mal implementada pode se tornar mais uma barreira entre o usuário e o patrimônio.

Este artigo tem como objetivo apresentar o projeto de digitalização e disponibilização do acervo do Arquivo Histórico do Centro Cultural da Cidade de Araranguá, localizado no extremo sul de Santa Catarina. Desenvolvido, de forma interdisciplinar, buscou a preservação e a difusão do acervo do Centro Cultural, composto por mais de 3.000 fotografias e mais de 5.000 documentos, oportunizado por pela Universidade Federal de Santa Catarina, por intermédio de um projeto de extensão, submetido à edital denominado Bolsa Cultura. Aqui, são relatadas as consequências dessa disponibilização virtual, quanto a sua conservação e difusão, bem como, a divulgação do patrimônio público cultural do Museu Histórico, direcionada ao intento de despertar o interesse em visitar o museu virtual e influenciar a visita ao museu físico (real).

Para alcançar tal objetivo, buscou-se embasamento teórico disponível na literatura, e a

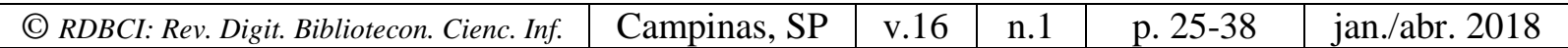


orientação de especialistas, responsáveis pelo projeto, que acompanharam seu desenvolvimento, tanto no que tange às ferramentas de Tecnologias da Informação e Comunicação (TIC), quanto às metodologias e boas práticas, em museus e Arquivos Históricos.

O Projeto "Digitalização do Acervo do Arquivo Histórico do Município de Araranguá" foi estruturado em dois estágios, a fim de organizar e digitalizar as imagens fotográficas e posteriormente, os documentos soltos. Ou seja, documentos que não pertencem a nenhum livro, jornal ou revista, existentes no Arquivo Histórico, constituído por fotografias, livros, jornais, revistas e outros documentos, que ilustram a memória da cidade e arredores.

A fim de mapear as circunstâncias do ambiente como um todo, inicialmente, o Arquivo do Centro Cultural foi submetido a uma avaliação de condição incipiente, para se traçar o plano de ação. Posteriormente, iniciou-se a aplicação e desenvolvimento do projeto, em que grande parte do acervo foi organizada, digitalizada e diminutamente reformada, de forma digital. Após as etapas de análise, organização, digitalização, restauração e catalogação, este acervo digital foi disponibilizado em um terminal pertencente ao próprio Centro Cultural. Em seguida, como forma de aumentar sua propagação, o acervo digitalizado foi integrado a um quiosque de informações, denominado Totem Digital. E finalmente, concluiu-se a disponibilização em uma plataforma web denominada Memórias Digitais de Araranguá, ambiente que assumiu o papel de extensão do Museu e do Arquivo Histórico da municipalidade.

\section{CONTEXTUALIZAÇÃo}

O Arquivo Histórico de Araranguá integra o Centro Cultural Artesã Máxima Astrogilda de Souza, que abriga ainda, o então Departamento de Cultura de Araranguá, agora denominado Secretaria de Cultura, e o Museu Histórico de Araranguá. Atualmente, o Centro Cultural está localizado em um prédio construído pelo Banco Nacional do Comércio S.A, posteriormente, utilizado pelo Banco Sul Brasileiro S.A e Banco Meridional S.A., um monumento histórico memorável para os araranguaenses, construído na década de 1940, adquirido pela Prefeitura Municipal de Araranguá, em 1997 e inaugurado, em meados de maio de 2000 (DEPARTAMENTO DE CULTURA, 2015).

A partir de 2005, a organização e o tratamento desse acervo pertencente ao Arquivo Histórico passaram a receber prioridade nas ações da Prefeitura de Araranguá que, por meio de parcerias com instituições de ensino da região, propiciou uma pré-organização em parte desse material. $\mathrm{O}$ acervo do Arquivo Histórico, basicamente formado por documentos antigos da municipalidade, coleções de jornais, e de fotos diversas do município e arredores, está disponível para visita, consulta e pesquisa pela comunidade. Desde a sua inauguração, foi reunido em uma pequena sala do prédio todo o material doado pela prefeitura e pelos cidadãos. Entretanto, apenas 5\% do acervo fotográfico, encontrava-se digitalizado e, dessa

\begin{tabular}{l|l|l|l|l|l|l}
\hline (C) RDBCI: Rev. Digit. Bibliotecon. Cienc. Inf. & Campinas, SP & v.16 & n.1 & p. 25-38 & jan./abr. 2018 \\
\hline
\end{tabular}


forma, acessível no computador do Centro Cultural.

Foi então, através do projeto "Digitalização do Acervo do Arquivo Histórico do Município de Araranguá", que se buscou conferir a organização de todas as imagens fotográficas e parte dos documentos soltos. Depois de ajustá-los em concordância com uma série de normas indicadas e adequadas pelos especialistas envolvidos no projeto, deu-se inicio ao processo de digitalização dos mesmos para enfim disponibiliza-los em formato digital.

\section{O PROJETO}

O Projeto de Digitalização do Acervo do Arquivo Histórico do Município de Araranguá deu-se em duas partes, ambas coordenadas pelo Professor Dr. Paulo Cesar Leite Esteves, com participação da bolsista Gabrielli Ciasca Veloso, acadêmica do curso de Bacharelado em Tecnologias da Informação e Comunicação da Universidade Federal de Santa Catarina, juntamente com a direção do Centro Cultural Artesã Máxima Astrogilda de Souza de Araranguá, em especial o diretor vigente do Arquivo Histórico. Este projeto teve o propósito de digitalizar o acervo fotográfico e documental pertencente ao Arquivo Histórico de Araranguá. A fim de promover a preservação do patrimônio, sem privar o público de seu acesso e ainda, estimular seu conhecimento de forma dinâmica, atrativa e interessante, buscaram-se diferentes ferramentas de TIC, que durante todas as etapas do projeto foram empregadas, tanto no processo de digitalização, como no método de disponibilização e divulgação.

Após a interação das participantes sobre a situação do Arquivo, foi necessário segmentar o projeto em duas fases a fim de organizar, normalizar e digitalizar, a maior parte possível de material disponível no Arquivo, pois o mesmo possui um grande volume tanto de documentos como de fotografias. Para tanto, na primeira fase do projeto, que teve duração de novembro de 2011 a outubro de 2012, foram selecionadas as imagens fotográficas, incluindo todas as imagens pertencentes ao Arquivo até o dia 31 de agosto de 2012. Essas foram devidamente organizadas e digitalizadas para posterior disponibilização, respeitando as diretrizes de catalogação e criação de legendas, propostas no projeto, onde cada fotografia era registrada através da sua legenda, que por sua vez mantinha correspondência entre o material físico e o virtual, isto é, a catalogação e organização virtual foram replicadas nas estantes onde o material físico é armazenado. A segunda fase do projeto de digitalização foi direcionada à organização, normalização e digitalização do acervo de documentos soltos, que não possuíam nenhum tipo de representação digital, e estavam previamente organizados por assunto. Essa segunda e última fase deu-se de março de 2013 a fevereiro de 2014; também, em conformidade com as diretrizes de catalogação e criação de legendas, como ratificado na descrição da fase anterior (VELOSO, 2015).

Visando propiciar uma melhor condição de conhecimento, manuseio do acervo e

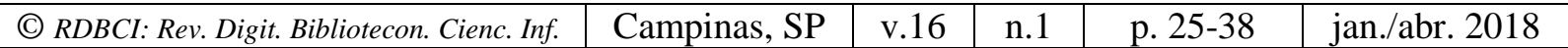


andamento dos processos, o projeto foi estruturado a fim de organizar e digitalizar documentos e imagens existentes no Arquivo Histórico da cidade, decorrendo em quatro etapas fundamentais, a saber: Análise, Identificação e Organização; Digitalização e Restauração; Catalogação; e por fim, Disponibilização do Acervo. Todas as etapas e suas especificidades são descritas na seção de Metodologia do Projeto.

\section{METOdOLOGIA DO PROJETO}

Decorrido o momento inicial de diagnóstico e apreensão das condições e limitações do acervo e do Arquivo Histórico, o projeto se desenvolveu dentro das etapas descritas a seguir.

\subsection{Análise, Identificação e Organização do Acervo}

Todo o acervo fotográfico constituído por 3.670 imagens fotográficas e exatos 5.165 documentos soltos, que compõem o acervo do Arquivo Histórico, foram analisados individualmente e organizados, segundo o assunto identificado em cada material. Conforme preconizam as técnicas de conservação de acervos históricos, foram utilizadas luvas e máscaras (cirúrgicas, não estéreis) durante o manuseio das fotografias, bem como dos demais documentos. Em muitos casos, foram encontrados dedicatórias ou lembretes escritos na fotografia, pois grande parte do acervo é oriunda de doação de pessoas da cidade. No entanto, houve dificuldade em encontrar informações que pudessem ajudar na criação da legenda e na segmentação por categorias de assunto, dado que, repetidas vezes, o que estava escrito na fotografia ou no envoltório de papel não era o que de fato a imagem representava. Em diferentes casos, essas palavras ou frases acabavam levando à confusão do que na prática poderia ser apenas um rascunho ou de fato informações verídicas referentes à fotografia. Por este motivo, algumas fotografias foram identificadas por comparação, com auxílio do historiador responsável pelo Arquivo.

Inicialmente, foi analisado o estado do acervo fotográfico e documental, que se encontrava em condições precárias de conservação e armazenamento. $\mathrm{O}$ acervo era disposto em prateleiras de madeira, material muito vulnerável à contaminação por cupins, e carecia de aparelho adequado (desumidificador) para garantir a qualidade apropriada do ar. A sala não possuía sequer uma porta para isolar o ambiente do acervo, do ambiente de trabalho dos funcionários do Centro Cultural.

Cada imagem fotográfica ou documento foi arquivado fisicamente e envolto em uma folha de papel branco, com as informações recolhidas no processo de identificação, escritas com lápis $6 \mathrm{~B}$, a fim de garantir que a fotografia ou documento não fosse danificado por qualquer resquício de tinta, mas que a informação ainda pudesse ser lida facilmente. As imagens de um mesmo assunto foram envelopadas sequencialmente, e esses envelopes distribuídos em caixas plásticas. Como uma parte inicial das fotografias já estava no processo de digitalização, esses arquivos foram constantemente revistos quanto à classificação e

\begin{tabular}{l|l|l} 
v.16 & n.1
\end{tabular}

p. $25-38$
jan./abr. 2018 
organização. As imagens digitais, encontradas no computador do Arquivo Histórico, foram organizadas com base nos mesmos critérios e movidas para um diretório específico, onde as imagens duplicadas e as cópias das fotografias físicas foram removidas. Cabe ressaltar que tal organização foi reiniciada várias vezes para acompanhar a constante inclusão de novos elementos ao acervo.

O acervo fotográfico físico está separado e armazenado em 53 pastas nominadas conforme os assuntos identificados nas fotografias, estas pastas estão agrupadas e armazenadas em um total de 08 caixas. A disposição final se deu de acordo com o volume, para melhor acondicioná-las sem desperdiçar espaço e evitando o sobrecarregamento, foram combinadas na mesma caixa as pastas que completavam a área total disponível. A relação das pastas por caixa é descrita no Quadro 1:

QUADRO 1. Relação de caixas e pastas das fotografias.

\begin{tabular}{|c|l|}
\hline Caixas & \multicolumn{1}{c|}{ Pastas } \\
\hline Caixa 01 & $\begin{array}{l}\text { Campo; Campo da Aviação; Casas; Arquitetura por Maurício Pereira; Concurso Foto Paisagem; } \\
\text { Construções; Coreto; Demolição; Enchentes; Hidroavião; Hospital Bom Pastor; Indústria; } \\
\text { Jardim; Maquinário Público; Maria Leofrísio; Plantas e Mapas; Ponte; Rádio; Rio Araranguá. }\end{array}$ \\
\hline Caixa 02 & Política - Manoel Mota; \\
\hline Caixa 03 & $\begin{array}{l}\text { Antigo Centro; Caminhão; Carro; Cidades; Embarcações; Esporte; Ferrovia; Lazer; Máquinas } \\
\text { Agrícolas; Monumentos; Ônibus; Sítio Arqueológico. }\end{array}$ \\
\hline Caixa 04 & $\begin{array}{l}\text { Artesanato; Biblioteca Pública Municipal Luiz Delfino; Escolas; Eventos Sete de Setembro; } \\
\text { Genaro Salvador; Igrejas; }\end{array}$ \\
\hline Caixa 05 & Bernardino de Senna Campos; Eventos; indígenas; \\
\hline Caixa 06 & Eventos Culturais; \\
\hline Caixa 07 & $\begin{array}{l}\text { Abertura Temporada 1987 - 1988; Balneários; Banda Municipal; Centro Cultural Máxima de } \\
\text { Souza; Cinema; Filmes; Museu; Pessoas; }\end{array}$ \\
\hline Caixa 08 & Cartões Postais; Eventos Religiosos; Fotos Aéreas; Imagens Sacras; Vias Públicas. \\
\hline
\end{tabular}
Fonte: Autores da pesquisa.

O Acervo de documentos está separado e armazenado em 16 pastas nominadas de acordo com os assuntos a que se referem, descritos no Quadro 2:

QUADRO 2. Assuntos referentes aos documentos.

\begin{tabular}{|l|l|l|}
\hline \multirow{4}{*}{ Assuntos } & Certificados & Generalidades \\
\cline { 2 - 3 } & Correspondências - Diversas & Registro de Imóveis \\
\cline { 2 - 3 } & Correspondências - Expedida & Requerimento - Baixa de Impostos \\
\cline { 2 - 3 } & Correspondências - Recebida & Requerimento - Certificados \\
\cline { 2 - 3 } & Correspondências - Telegramas Diversos & Requerimento - Construção \\
\cline { 2 - 3 } & $\begin{array}{l}\text { Correspondências - Telegramas } \\
\text { Expedidos }\end{array}$ & Requerimento - Diversos \\
\cline { 2 - 3 } & $\begin{array}{l}\text { Correspondências - Telegramas } \\
\text { Recebidos }\end{array}$ & $\begin{array}{l}\text { Requerimento - Transferência - } \\
\text { Tratamento de Saúde }\end{array}$ \\
\cline { 2 - 3 } & Ficha de Eleitor & $\begin{array}{l}\text { Requerimento - Tratamento de Saúde } \\
\text { - Construção }\end{array}$ \\
\hline
\end{tabular}

Fonte: Autores da pesquisa.

Os documentos digitalizados encontram-se nas pastas de assunto "Certificados" e "Correspondências Recebidas", pertencentes ao arquivo até meados de janeiro de 2014.

\begin{tabular}{|c|c|c|c|c|c|}
\hline (C) RDBCI: Rev. Digit. Bibliotecon. Cienc. Inf. & Campinas, SP & $\mathrm{v} .16$ & n.1 & p. $25-38$ & jan./abr. 2018 \\
\hline
\end{tabular}


Somente nessas duas pastas existe um acervo superior a 6.000 elementos; porém, dado o grande volume de documentos e o prazo restrito, exatamente 5.165 documentos foram submetidos aos processos deste projeto.

\subsection{Digitalização e Restauração do Acervo}

Após o processo de organização, iniciou-se a digitalização do acervo, em que se consideraram as poucas imagens já digitalizadas; porém, por conta da baixa qualidade de resolução, estas foram digitalizadas novamente, nos padrões estabelecidos neste projeto. As fotografias e documentos foram digitalizados em resolução de 600 DPI (Dots Per Inch, em tradução livre para o português: "Pontos por Polegada"), com exceção daquelas de dimensões muito pequenas, em média, menores a $6 \mathrm{~cm}^{2}$, em que se utilizou a resolução de 1200 DPI.

O nome desenvolvido para cada arquivo é composto por um número sequencial para cada assunto, seguido do nome da pasta (que se refere ao assunto do registro histórico), da descrição do local, data e pessoas, no caso dos registros fotográficos. O equipamento utilizado para a digitalização foi o scanner de mesa digital HP Scanjet 5590, pertencente ao próprio Centro Cultural. Os arquivos digitais foram salvos no computador do Arquivo Histórico e em dois HDs externos como método de backup.

Durante a identificação e organização e sob a supervisão do historiador responsável pelo arquivo, algumas restaurações simples foram realizadas nas fotografias, como troca de invólucro inadequado quando o papel apresentava escrita à caneta ou tamanho impróprio e ainda, a retirada de restos de cola e fitas adesivas, com a utilização de bisturi. Nos arquivos resultantes da digitalização, observou-se a necessidade da restauração digital de algumas fotografias danificadas pelo tempo e armazenamento precário; então, iniciou-se o processo de restauração digital, que buscou o aperfeiçoamento da qualidade da imagem, remoção digital de manchas e marcas de dobradura sem retirar aspectos que caracterizam o registro histórico, como dedicatórias escritas na fotografia. Neste processo de restauração digital foram utilizados os softwares Adobe Photoshop e Microsoft Office Picture Manager.

\subsection{Catalogação do Acervo}

A legenda e nome do arquivo digital referente ao acervo fotográfico são compostos por 08 informações, descritas na seguinte ordem: número sequencial que se refere à fotografia, assunto principal, assunto secundário, evento, data, pessoas presentes na imagem, fotógrafo responsável pelo registro e lugar registrado. Em diversos arquivos algumas das informações não estavam disponíveis, seja por não haver informações ou registros na fotografia, ou ainda, por não ser possível identifica-las, seja por falta de informação ou por danos na imagem.

A contagem do número sequencial da legenda de cada fotografia inicia a cada ano, pertencente a cada assunto, de cada caixa. Ou seja, toda caixa de cada assunto, terá a primeira

\begin{tabular}{l|l|l} 
v.16 & n.1
\end{tabular}

p. $25-38$
jan./abr. 2018 
fotografia com o número sequencial "001". Por exemplo: "266 Esporte Motociclismo IV Km Arrancada de Moto 10-02-1985 Balneário Arroio do Silva”. O detalhamento da composição da legenda das fotografias é apresentado no Quadro 3.

QUADRO 3. Composição da legenda das fotografias.

\begin{tabular}{|l|l|}
\hline \multicolumn{2}{|c|}{ Composição da legenda da fotografia } \\
\hline Número sequencial & 266 \\
\hline Assunto principal & Esporte \\
\hline Assunto secundário & Motociclismo \\
\hline Evento & IV Arrancada de Moto \\
\hline Data & $10-02-1985$ \\
\hline Pessoas identificadas na fotografia & Informação indisponível \\
\hline Fotógrafo & Informação indisponível \\
\hline Lugar & Balneário Arroio do Silva \\
\hline \multicolumn{2}{|l}{ Legenda Final: “266 Esporte Motociclismo IV Arrancada de Moto 10-02-1958 Balneário Arroio do } \\
Silva”
\end{tabular}

Fonte: Autores da pesquisa.

Os dois primeiros campos que compõem a legenda são campos obrigatórios, isto é, estão presentes em todas as fotografias. Os demais campos, só estarão presentes na legenda quando existir a informação, conforme a descrição de todos os campos, que compõem a legenda:

$1^{\circ}$ - número sequencial referente à fotografia: está para a fotografia como um identificador individual dentro da pasta a que pertence, um nome próprio, válido apenas quando junto às demais informações da legenda, precedido da descrição do assunto principal identificado na fotografia. Este campo é obrigatório na legenda do arquivo digital;

$2^{\circ}$ - assunto principal identificado na fotografia. Este item também é descrito em todas as legendas dos arquivos digitais;

$3^{\circ}$ - assunto secundário identificado na fotografia, quando existir e tiver a possibilidade de ser identificado com clareza;

$4^{\circ}$ - descrição do tipo ou nome do evento representado na fotografia, quando a informação estiver disponível;

$5^{\circ}$ - data em que a fotografia foi feita, podendo ser o dia, o mês e o ano, ou ainda apenas um destes campos, como por exemplo, apenas o ano;

$6^{\circ}$ - pessoas presentes na imagem, quando houver e quando se conseguir identificar e conhecer os nomes das pessoas presentes na fotografia;

$7^{\circ}$ - fotógrafo responsável pela feitura da fotografia;

$8^{\circ}$ - local representado na imagem, como rua, bairro, cidade, estado ou país.

Estes quatro últimos elementos: "Data", "Pessoas", "Fotógrafo" e "Local", são elementos mais raros de serem descritos, porém podem ser encontrados na própria fotografia ou através de descoberta por pesquisa em outros documentos ou, ainda, por informações de pessoas que tenham alguma relação com a fotografia.

Quanto aos documentos soltos, suas legendas (ou nomes dos arquivos digitais) são 
compostas por 04 informações, desenvolvidas na seguinte ordem: ano, número sequencial, páginas e lados do documento (frente e verso). O campo "Páginas" só é necessário quando o documento é formado por mais de uma página. E o campo "Lados do documento", somente é necessário quando o documento tem informações dos dois lados. Porém, os dois primeiros campos, que compõem a legenda são campos obrigatórios, ou seja, estão presentes em todas as legendas de todos os documentos, conforme sua descrição:

$1^{\circ}$ - ano a que o documento se refere precedido da palavra reservada "Ano". Por exemplo: "Ano 1983";

$2^{o}$ - número sequencial referente ao documento: este está para o documento como um identificador individual, um nome próprio, válido apenas quando junto às demais informações, precedido da palavra reservada "Documento". Por exemplo: "Documento 001". A contagem do número sequencial da legenda de cada documento inicia a cada ano pertencente a cada assunto de cada caixa, ou seja, toda caixa de cada assunto, terá o primeiro documento com o número sequencial " 001 ”, tal como pode se observar na organização das fotografias;

$3^{\circ}$ - número referente à página digitalizada, com menção a quantidade total de páginas do documento, antecedido da expressão reservada "Página x de y", quando necessário, ou seja, apenas nos casos em que o documento possuir mais de uma única página. Por exemplo: "Página 1 de 2";

$4^{\circ}$ - entre parênteses a descrição de "frente" ou "verso", quando necessário, isto é, somente nos casos em que exista material histórico relevante nos dois lados do documento. Este deve ser disposto como último item ou ainda, se o documento constar informação de "Página", deve ser disposto ao lado do número da página atual do documento. Consequente e inevitavelmente, todo documento que possuir "verso", deve possuir outro documento digital "frente". Por exemplo: "Página 1 (verso) de 2" e "Página 1 (frente) de 2", ou ainda "(verso)" e "(frente)", como descrito no Quadro 4.

QUADRO 4. Exemplos de legenda dos documentos.

\begin{tabular}{|l|l|}
\hline \multirow{2}{*}{ Exemplos de legenda } & "Ano 1983 - Documento 001 - Página 1 (verso) de 2" \\
\cline { 2 - 2 } & "Ano 1983 - Documento 002 (frente)" \\
\cline { 2 - 2 } & "Ano 1983 - Documento 003" \\
\hline
\end{tabular}

Fonte: Autores da pesquisa.

Neste caso, para a construção da legenda, não houve a necessidade de se fazer pesquisas para além do próprio material digitalizado. As informações de ano, número de páginas e lados do documento foram analisadas no próprio documento e acrescentadas à legenda quando necessário.

\subsection{Disponibilização do Acervo}

Inicialmente, o material digitalizado foi disponibilizado, exclusivamente, no computador do Centro Cultural, disposto na sala do diretor do Arquivo Histórico, o que

\begin{tabular}{l|l|l} 
v.16 & n.1
\end{tabular}

p. $25-38$ jan./abr. 2018 
facilitou a pesquisa in loco e a busca por material específico. No entanto, após a finalização do projeto, por meio de outro projeto da Universidade Federal de Santa Catarina, foi idealizado e construído o Totem Digital, um quiosque de informação, concebido a partir de hardware reciclado e doado, destinado ao patrimônio digital do Centro Cultural de Araranguá. Este projeto promove a interação tecnológica da história local com os visitantes do Museu Histórico, através de um hardware simples e com suporte ao armazenamento de informações como: dados do museu histórico, registros em geral, documentos, materiais, mapas, dentre outros elementos multimídia. É uma importante aplicação multimídia, que tem por objetivo ser uma plataforma de exposição do patrimônio do Centro Cultural, de forma digitalizada e virtual, desenvolvida sob a orientação de professores da Universidade Federal de Santa Catarina e alunos de graduação, bolsistas do projeto. O hardware do totem é fruto de material reciclado e doado, com a intenção de dar ao projeto, um caráter não somente sociocultural, mas também, ecológico.

A fim de prover a interação destes dois projetos - digitalização do acervo (conteúdo), e construção física do totem (plataforma) - surge um terceiro projeto, este de integração do acervo digitalizado do Arquivo Histórico de Araranguá com o Totem Digital, com a intenção de projetar e avaliar um Modelo de Aplicação Multimídia Interativa para o Totem Digital. Ou seja, idealizar, desenvolver e avaliar uma interface de navegação para o Totem Digital e, por meio dela, acessar o acervo digital do Arquivo Histórico.

Este terceiro projeto: “Avaliação de Aplicações Multimídia Interativas para Quiosque de Informações: Totem Digital para o Museu Histórico de Araranguá" (VELOSO, 2015), origina-se da união dos dois projetos citados anteriormente, que foram responsáveis por fornecer o conteúdo e a plataforma, respectivamente. A fim de, por intermédio das TICs, atualizar a forma de acesso ao acervo do Centro Cultural, este terceiro projeto, propõe-se a realizar o planejamento, elaboração e execução de um modelo de aplicações multimídia. Por meio de uma interação eficaz, eficiente e satisfatória dentro dos principais requisitos de usabilidade, o Totem Digital foi projetado, construído e avaliado para prover a interação humano-computador, servindo como hospedeiro do acervo digital do Arquivo Histórico de Araranguá.

No entanto, o objetivo de disponibilizar e divulgar o patrimônio público cultural do município de Araranguá em formato digital, só foi concluído quando em novo projeto, desenvolvido em 2016, como resultado de um trabalho de conclusão de curso (TCC), do curso de Bacharelado em Tecnologias da Informação e Comunicação da Universidade Federal de Santa Catarina, a plataforma web "Memórias Digitais de Araranguá" (ALMEIDA; CÂNDIDO, 2016) (disponível no endereço: http://labmidiaeinteratividade.ufsc.br/memoriasdigitais/tdigital/), disponibilizou na internet todo o acervo digitalizado desde o início de 2014. Por meio da mesma interface disponibilizada no Totem Digital e avaliada no terceiro projeto descrito neste trabalho: "Avaliação de Aplicações Multimídia Interativas para Quiosque de Informações: Totem

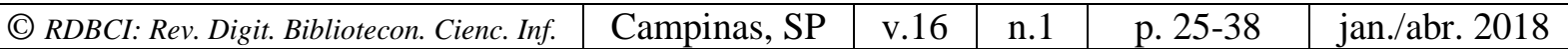


Digital para o Museu Histórico de Araranguá" desenvolveu-se o site citado. Atualmente, o "Memórias Digitais de Araranguá" está ativo e é uma das plataformas utilizadas na pesquisa de mestrado da autora principal deste trabalho.

\section{CONSIDERAÇÕES FINAIS}

De um modo geral, o museu é visto como o local que conserva, estuda, comunica e expõe os testemunhos materiais deixados ao longo de gerações. A instituição é considerada um local à serviço da sociedade, ou melhor, como um espelho da sociedade (ROMAN, 1992). Entretanto, a visita ao museu está cada vez menos lembrada pela população. A pesquisa em Arquivos (instituição) aos arquivos históricos (documentos disponíveis em Arquivos) há tempos não é mais a principal maneira de se conhecer a história de um local, de um personagem ou de um fato (NOGUEIRA, 2006). Sob o ponto de vista de Muchacho (2005), "O museu da atualidade está a enfrentar um desafio constante e primordial: a comunicação com o seu público.”.

Sendo assim, o processo de digitalização deste patrimônio coletivo, destina-se a fornecer um novo canal de comunicação, por meio da criação e da efetivação de um meio de acesso virtual ao acervo do museu histórico de Araranguá, viabilizando novas formas de interação e colaboração do Arquivo Histórico com a população e vice-versa. Um dos efeitos dessa inovação é a possibilidade de doação virtual de material, haja visto que muitos doadores têm o desejo de contribuir com o acervo do Arquivo, mas não querem se desfazer do material, seja ele fotografia, documento ou objeto. Desta forma, o doador dispõe apenas de um registro virtual do seu item ao Museu, sem doar o item físico (real). Outras consequências práticas podem ser observadas, tal como o método de busca dos pesquisadores: agora é possível fazer uma busca inicial ao acervo digital para depois acessar o material físico que se encontra guardado e protegido de ações do tempo e da manipulação excessiva sem proteção.

Posto isso, o que se pode constatar neste projeto é que, dado seu caráter interdisciplinar, muitos colaboradores foram agregados, tanto no período do seu desenvolvimento quanto após sua disponibilização, por meio da criação de uma aplicação web. No primeiro momento, colaboraram com relação ao auxílio à tomada de decisão sobre os equipamentos que seriam utilizados, e procedimentos de cuidado com a manipulação do acervo; em seguida, contribuíram e ainda contribuem, para tornar o ambiente web mais amigável e atrativo, tanto para o visitante, antigo frequentador do Centro Cultural, quanto para as crianças em idade escolar, que têm maior acesso, em diferentes contextos do seu cotidiano, a este material, tão valoroso cultural e historicamente.

Assim, este projeto bem como diferentes outros, foram e estão sendo elaborados e desenvolvidos, dentro e fora da universidade. E, cada vez mais, essas ações têm servido de objeto de estudo e incentivo ao resgate e à valorização da cultura local. 
Por fim, considerando a etimologia da palavra patrimônio, ligada à ideia de herança, é possível afirmar que - o projeto, em todas as suas fases e inspirando outros projetos citados neste trabalho - empregou o propósito de facilitar o acesso e incentivar o respeito e a valorização, ao legado desta cidade tão rica culturalmente e, ao mesmo tempo, tão desatenta a sua importância.

\section{REFERÊNCIAS}

ALMEIDA, Juliano Oliveira de; CÂNDIDO, Rafael. Memórias digitais de Araranguá: desenvolvimento de uma aplicação multimídia para web do museu histórico de Araranguá. 2016. 91 f. TCC (Graduação) - Curso de Tecnologias da Informação e Comunicação, Universidade Federal de Santa Catarina, Araranguá, 2016. Disponível em: <https://repositorio.ufsc.br/xmlui/handle/123456789/165335>. Acesso em: 07 dez. 2017.

DEPARTAMENTO DE CULTURA (Araranguá). Centro Cultural de

Araranguá. Disponível em: <http://culturaararangua.blogspot.com.br>. Acesso em: 05 out. 2017.

MUCHACHO, Rute. O Museu Virtual: as novas tecnologias e a reinvenção do espaço museológico, 2005. Disponível em: < http://www.bocc.ubi.pt/pag/muchacho-rute-museuvirtual-novas-tecnologias-reinvencao-espaco-museologico.pdf > Acesso em: 05 out. 2017.

NOGUEIRA, Marta. A utilização das tecnologias da informação e comunicação na concretização e desenvolvimento de projetos de difusão do património documental: as exposições. 2006. Apresentado no $2^{\circ}$ Foro Social de Información, Documentación y Bibliotecas. Disponível em: <http://repositorio.ul.pt/handle/10451/3190>. Acesso em: 05 out. 2017.

ROMAN, L. S. Politics and museums 1. In P. Boylan Ed. Museums 2000: politics, people, professionals and profit. London: Routledge, 1992. 25p.

VELOSO, Gabrielli Ciasca. Avaliação da Interface de Interação para a Aplicação Multimídia do Totem Digital do Museu Histórico de Araranguá. 2015. 139 f. TCC (Graduação) - Curso de Tecnologias da Informação e Comunicação, Universidade Federal de Santa Catarina, Araranguá, 2015. Disponível em: <https://repositorio.ufsc.br/xmlui/handle/123456789/133758>. Acesso em: 05 out. 2017.

\section{AGRADECIMENTOS}

Agradecemos à Revista Digital de Biblioteconomia e Ciência da Informação (RDBCI) pela honra de participar de um periódico comprometido com a democratização mundial do conhecimento, a todos os que ajudaram a equipe na elaboração deste trabalho: os professores orientadores e demais envolvidos, bem como toda a comunidade acadêmica, à própria Universidade Federal de Santa Catarina, que proporcionou não só sua infraestrutura, como a

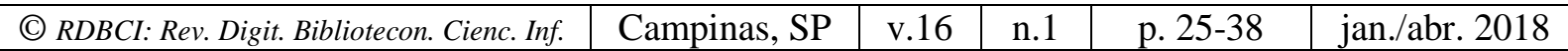


oportunidade de adquirir e aplicar os conhecimentos científicos que pudemos acessar; aos colegas de laboratório e de projeto, que cooperaram e colaboraram com este trabalho, e principalmente, à direção do Centro Cultural Artesã Máxima Astrogilda de Souza de Araranguá, em especial, ao diretor vigente do Arquivo Histórico, Daniel Vieira, e à servidora Linda, que foram atenciosos e dedicados ao nosso trabalho.

E por fim, a CAPES pela concessão de bolsa da principal autora deste artigo, durante o período do seu mestrado e ao LABeGIS, laboratório que tem dado continuidade à parte das ações, referentes ao patrimônio histórico da cidade de Araranguá.
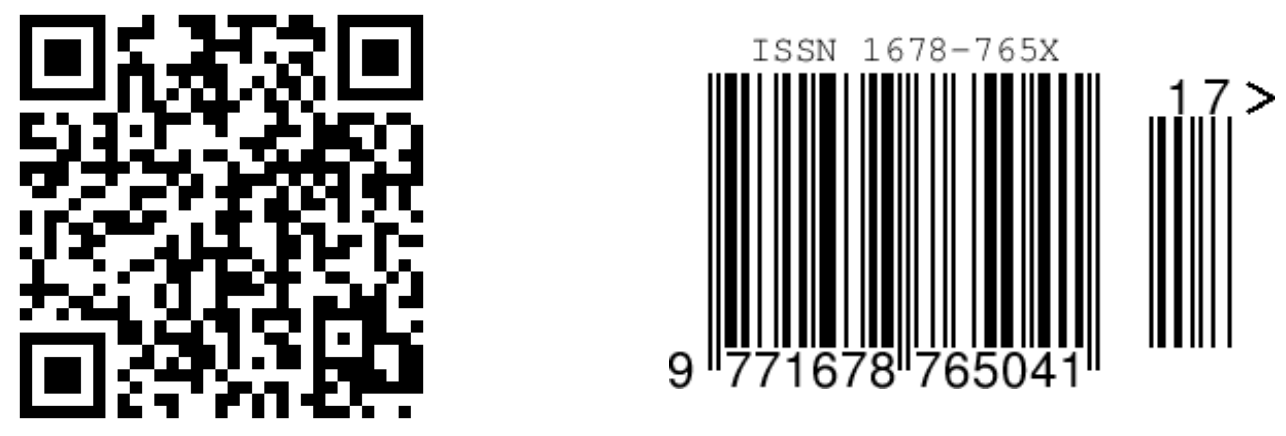